\title{
CARMICHAEL, Ann G., RATZAN, Richard M., Medizin in Literatur und Kunst
}

Isabelle von Bueltzingsloewen

\section{OpenEdition}

Journals

Édition électronique

URL : http://journals.openedition.org/ifha/1569

DOI : 10.4000/ifha.1569

ISSN : 2198-8943

Éditeur

IFRA - Institut franco-allemand (sciences historiques et sociales)

\section{Référence électronique}

Isabelle von Bueltzingsloewen, « CARMICHAEL, Ann G., RATZAN, Richard M., Medizin in Literatur und Kunst », Revue de l'IFHA [En ligne], Date de recension, mis en ligne le 01 janvier 1996, consulté le 22 septembre 2020. URL : http://journals.openedition.org/ifha/1569; DOI : https://doi.org/10.4000/ifha. 1569

Ce document a été généré automatiquement le 22 septembre 2020.

(C)IFHA 


\title{
CARMICHAEL, Ann G., RATZAN, Richard M., Medizin in Literatur und Kunst
}

\author{
Isabelle von Bueltzingsloewen
}

Ce livre traduit de l'américain (pourquoi pas en français?) ne pourra que ravir tous ceux qui s'intéressent à la représentation de la médecine et de la maladie, dans l'art mais aussi dans la littérature. C'est en effet l'une des grandes originalités de l'ouvrage que de croiser approche iconographique et approche littéraire d'un thème qui, depuis l'Antiquité jusqu'à nos jours, a inspiré le pinceau et la plume des plus grands artistes: Pétrarque et Holbein le Jeune, Montaigne et Rembrandt, Molière et Poussin, Heine et Delacroix, Catherine Mansfield et Munch, Léon Tolstoï et Böcklin ou encore van Gogh, Malraux, Dix, Goya, Picasso, Dubuffet... A.C., professeur au Centre d'Histoire de la Médecine de l'université d'Indiana (Bloomington) et R.R., professeur de médecine à l'université du Connecticut (Farmington) ont réalisé un travail remarquable de collecte de documents, puisant dans les fonds de tous les grands et moins grands musées du monde ainsi que dans des collections privées. Ils nous permettent ainsi de revoir quelques scènes familières, »La guérison de la folie« de Bosch (1490), »Le vieil homme et son petit-fils« de Ghirlandaio (fin XVe s.), »La leçon d'anatomie du Dr. Nicolas Tulp« de Rembrandt (1632) ou "L'enfant malade« de Gabriel Metsu (1660) mais surtout de découvrir un matériel iconographique ou sculptural beaucoup moins connu en particulier, pour la période médiévale, des fresques et de nombreuses enluminures et miniatures tirées des manuscrits de traités de médecine, de chirurgie ou de botanique, européens mais aussi chinois, japonais ou persans. La qualité des 235 reproductions, dont 145 en couleur est un autre motif d'admiration. On regrettera en revanche, même si l'ouvrage s'adresse au grand public, que les auteurs se soient montré aussi timorés dans le travail de commentaire de ce riche matériau; comment se satisfaire, lorsqu'elles existent, des quelques lignes qui accompagnent chaque reproduction et qui négligent la dimension artistique de l'œuvre, laissant à penser que ces représentations de la maladie ne peuvent être lues que comme des documents informatifs. Pour la partie littéraire de l'ouvrage, on s'étonnera également de la négligence des auteurs qui, dans 
de nombreux cas, s'abstiennent de mentionner la date de publication originale des ouvrages cités, se contentant de renvoyer aux rééditions les plus récentes.

Isabelle von BUELZINGSLOEWEN 